
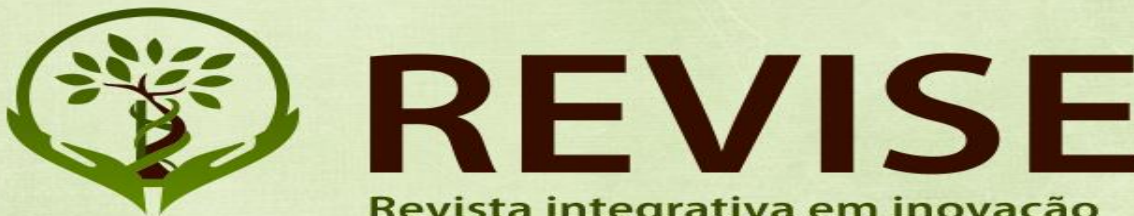

Revista integrativa em inovação tecnológica nas ciências da saúde

ISSN: $2179-6572$

\title{
Minicurso: USO DE PREPARADOS HOMEOPÁTICOS NA PRODUÇÃO DE ALIMENTOS AGROECOLÓGICOS E FITOTERÁPICOS
}

\author{
Myriam Raffaella Rabelo Criscuolo \\ $U F R B$
}

\begin{abstract}
RESUMO
O artigo registra os cursos do congresso internacional de inovação tecnológica nas ciências da saúde: a sustentabilidade das práticas integrativas a agroecologia, mais especificamente o minicurso Uso de Preparados Homeopáticos na Produção de Alimentos Agroecológicos e Fitoterápicos. O minicurso enfatiza que os princípios da prática homeopática e da agroecologia buscam o equilíbrio dos organismos vivos fortalecendo a energia vital e a convivência do ser humano com ambiente. $O$ evento aconteceu de 15 a 18 de novembro de 2017 no IFBA SAJ sob a direção da Universidade Federal do Recôncavo da Bahia.

Palavras-chave: Agroecologia. Homeopatia. Fitoterápicos. Sustentabilidade.
\end{abstract}

\begin{abstract}
The article records the courses of the international congress on technological innovation in health sciences: the sustainability of integrative practices in agroecology, more specifically the short course Use of Homeopathic Preparations in The Production of Agroecological Foods And Phytotherapic. The short course emphasizes that the principles of homeopathic practice and agroecology seek the balance of living organisms by strengthening the vital energy and coexistence of human beings with the environment. The event took place from November 15 to 18, 2017 at IFBA SAJ under the direction of the Federal University of Recôncavo da Bahia.

Keywords: Agroecology. Homeopathy. Herbal medicines. Sustainability.
\end{abstract}

Homeopatia. Revista Revise, vol 3, no Fluxo Contínuo, p.11-13. 

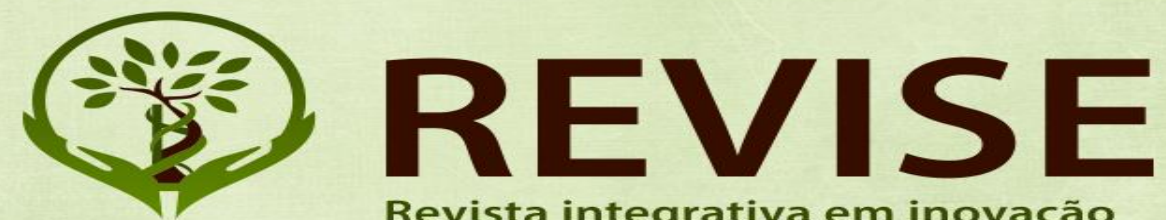

O modelo de agricultura predominante baseado no monocultivo e insumos industriais traz uma degradação socioambiental, como nunca na história, e por isso se faz necessário o fazer de agriculturas que respeitem os direitos da natureza, a biodiversidade e a dignidade humana. Diante desse contexto, e na busca por uma agricultura produtiva, voltada para a ética, a segurança alimentar dos povos e a qualidade ambiental duas ciências são destacadas: Agroecologia e Homeopatia na Agricultura. O acesso ao conhecimento da Homeopatia está de acordo com os princípios que regem a Agroecologia, pois ambas as ciências buscam o equilíbrio dos organismos vivos fortalecendo a energia vital dos organismos e a convivência harmônica do ser humano com ambiente. Além disso, uso de preparados homeopáticos na agricultura é um passo intermediário para a produção agroecológica, é vista como tecnologia social que pode auxiliar na transição agroecológica. No contexto da Agroecologia, a Homeopatia Agrícola, em consonância com os seus princípios, busca elevar o nível de sustentabilidade, a resiliência e a resistência em relação aos efeitos externos abaladores dos agroecossistemas, aumentar a autonomia dos agricultores e preservar o meio ambiente com o manejo preservacionista dos recursos naturais. Atualmente, sabe-se que é comum o seu uso na agricultura, para tratamentos de plantas, solos, água. A partir de uma relação de experiências junto às famílias agrícolas acredita-se que as preparações homeopáticas promovem respostas na força vital dos organismos resultando nos processos adaptativos, promovendo a homeostase de forma sistêmica nos organismos vivos. Atualmente os preparados homeopáticos são usados para tratamento de solos, água, controle de doenças e pragas, provendo uma resposta no desenvolvimento e proteção das culturas. Considerada uma tecnologia limpa, devido à ausência de intoxicação do ambiente, tem condições, a partir da ampla divulgação, de substituir

Homeopatia. Revista Revise, vol 3, $n^{o}$ Fluxo Contínuo, p.11-13. 



Revista integrativa em inovação tecnológica nas ciências da saúde

ISSN: 2179-6572

insumos químicos de alto custo de produção e trazer melhorias na qualidade de vida da família agrícola.

\section{EMENTA}

Diagnóstico de problemas recorrentes na propriedade; Princípios da homeopatia; Preparo de homeopatia (nosódios) para solo, água, plantas e animais; fitoterápicos versus homeopatia; Relato de experiências do uso de homeopatia no campo; Homeopatia e produção de alimentos agroecológicos.

\section{OBJETIVOS}

Partilhar o conhecimento. Demonstrar o valor dos preparados homeopáticos na qualidade de vida. Orientar sobre o uso racional de preparados homeopáticos nos ambientes e nos organismos vivos. Introduzir o estudo e a prática sobre homeopatia.

\section{MATERIAL DE USO}

2 litros de álcool;

Vidros (6 conta-gotas 30ml, 3 vidros transparentes de 200ml);

Papel alumínio.

Tesoura.

\section{MATERIAL DIDÁTICO}

Cartilha de Homeopatia - Instruções práticas geradas por agricultores sobre o uso de homeopatia no meio rural (Departamento de Fitotecnia da Universidade Federal de Viçosa - Prof. Vicente Casali).

Homeopatia. Revista Revise, vol 3, $n^{o}$ Fluxo Contínuo, p.11-13. 